\title{
Studies on the Epidemiology of Escherichia coli Infections. IV. Evidence for a Nosocomial Flora*
}

\author{
Roger P. Kennedy, James J. Plorde, and Robert G. Petersdorf \\ (From the Department of Medicine, University of Washington School of Medicine and King \\ County Hospital, Seattle, Wash.)
}

Studies of the epidemiology of infections due to Escherichia coli have been made possible by the availability of the serologic typing methods based primarily on the work of Kauffmann (1) and Edwards and Ewing (2). Application of these methods has clearly demonstrated the existence of a small group of serologically specific strains that have been responsible for infantile diarrhea (3). Some of these diarrheal strains probably originate in the hospital (4), although community dissemination also occurs (5). Whether there is an analogous situation with respect to $E$. coli causing extraintestinal infection is less clear. It has been demonstrated that only a handful of the more than 140 E. coli $O$ groups are responsible for the major portion of nonenteric coliform infections $(6,7)$. These $O$ groups include $04,06,075$, and less commonly 01,025 , and $016-062(6,7)$. To date, it has not been possible to relate the prevalence of these few specific strains in extraintestinal E. coli infections to either enhanced virulence or to nosocomial dissemination. In fact, early observations suggested that these strains cause the majority of infections simply because they are more prevalent in the environment (6).

Since the major reservoir of $E$. coli is the gastrointestinal tract, a comparison of the serologic groups of $E$. coli found in the stool of hospitalized and nonhospitalized individuals should demonstrate the existence of a "hospital-based" flora. Furthermore, relating the rates of infection with E. coli of different serologic groups to the prevalence of these groups in the stool of the same pop-

\footnotetext{
* Submitted for publication July 21, 1964 ; accepted October 14, 1964.

This investigation was supported by a training grant (AI 146-04) from the Institute of Allergy and Infectious Diseases, U. S. Public Health Service.

This work was presented in preliminary form at the Second International Conference on Pyelonephritis, Boston, Mass., June 4, 1964.
}

ulation should permit a demonstration of the propensity of these strains to cause extraintestinal infection.

\section{Methods}

Populations studied. Two groups of patients comprise the subject of this communication. The first (group A) consisted of 74 individuals. Thirty-eight had been hospitalized on the wards of the King County Hospital for more than 10 days, and 36 were seen at the Seattle King County Health Department, none of whom had been in contact with the hospital for at least 6 months and usually longer. Both the 38 hospitalized patients and the 36 individuals representing the community consisted of approximately $50 \%$ males and ranged in age from 25 to 75 years. All hospitalized patients were on the medical and neurologic services and had a variety of diseases such as pneumonia, hepatitis, hypertension, cerebrovascular disease, and heart failure. Approximately $50 \%$ of these patients had received antibiotics; none of the "community group" had taken antimicrobials. A single stool culture was obtained from each of these 74 individuals.

The second group (group B) consisted of 102 men hospitalized on urologic wards of the King County Hospital for prostatic surgery. Serial stool, urethral, and urine cultures were obtained from these patients. Each patient had an average of approximately 3.7 stool or urethral cultures and approximately seven to eight urine cultures during the course of hospitalization. Additional stool cultures were obtained from some patients following discharge from the hospital.

Sampling techniques. All stool cultures were obtained by rectal swab. Urethral cultures were obtained by passing a moistened, cotton-tipped applicator approximately $2 \mathrm{~cm}$ into the urethral orifice, alongside the indwelling catheter if one was present. Urine samples were obtained either by the clean-voided technique or by aspiration from the catheter drainage tube with a small gauge needle.

Bacteriology. Stool samples were plated directly on desoxycholate agar plates, and an average of 20 colonies was picked for further study. Previous studies have demonstrated that this number of colonies provides a representative sample of the bacterial population of stool (8). Urethral cultures were handled similarly, but five colonies were selected for study. All urine samples were cultured quantitatively by the pour plate technique. Significant bacteriuria was defined as the presence of 


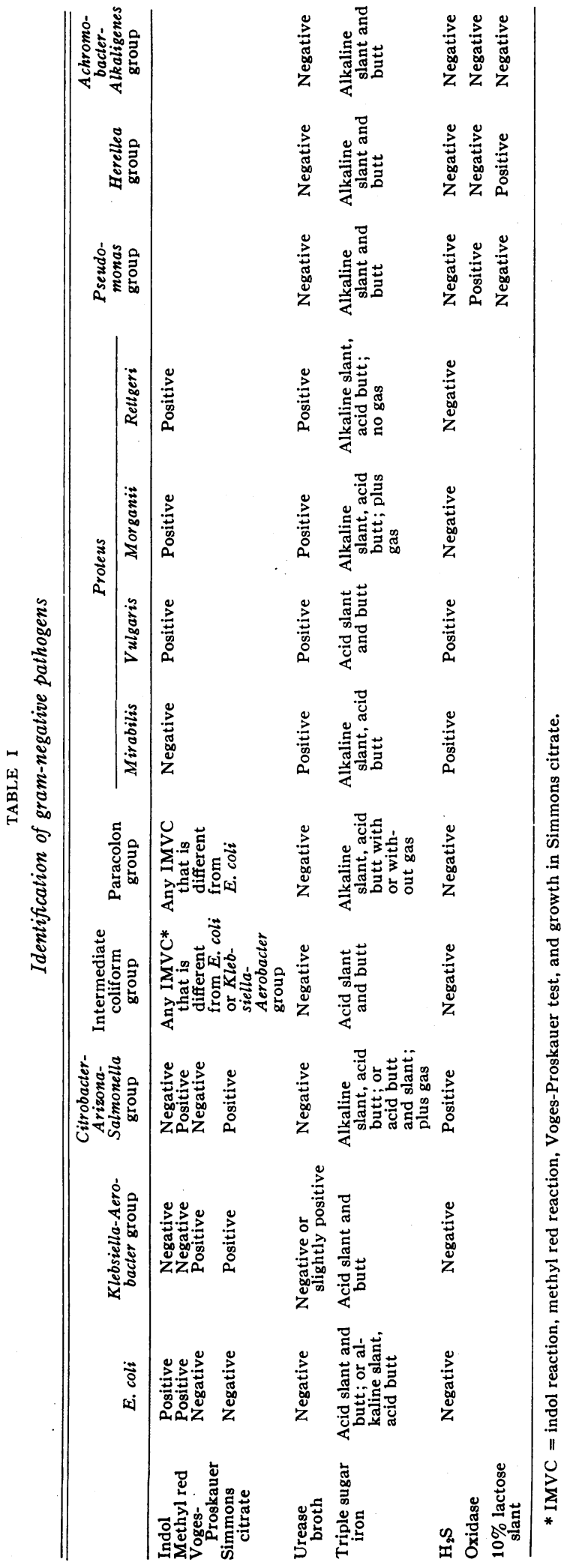

$10^{5}$ or more bacteria per $\mathrm{ml}$ of urine. In population group A only $E$. coli was studied. These organisms were identified biochemically, and serologic typing was carried out on each colony identified as $E$. coli according to methods described in detail in a previous publication from this laboratory (6). In study group B (patients admitted for prostatectomy) aerobic gram-negative rods as well as $E$. coli were isolated and identified biochemically. Because the methods for identifying gram-negative bacteria vary considerably in different laboratories, the classification in use in our laboratory and the bacteriology employed will be presented in some detail.

Identification of gram-negative rods. All cultures were initially streaked on desoxycholate agar plates. Each colony with a unique appearance was inoculated into indol medium, methyl red medium, Voges-Proskauer medium, and on a Simmons citrate slant. These tests were read at the end of 48 hours. In addition, each colorless colony that appeared unique on the desoxycholate plate was inoculated into triple sugar iron medium and urease broth, and the tests were read at the end of 24 and 48 hours. Organisms that had both an alkaline slant and butt on the triple sugar iron medium were inoculated onto $10 \%$ lactose slants and were also tested with oxidase. The classification for these gram-negative organisms is summarized in Table I. No specific tests to separate Salmonella, Arizona, and Citrobacter were performed.

Analysis of data. In study group A the total number of colonies was used in the tabulations. This was the practice followed in previous publications from this laboratory (6). In study group B, the occurrence of a strain in a patient, regardless of the number of colonies present or the number of cultures in which it occurred, was used in the tabulations. Using this analysis obviated the bias that is introduced when 20 colonies in the same stool sample are all of one serologic type as opposed to another stool sample that might contain as many as four or five serologic types. In this study (group B), a strain was defined as "persisting" if it was present continually in the stool after initial recovery and remained in the stool throughout the period of observation in the hospital. Strains discovered on the final stool culture were excluded. Rates of urinary tract infection and urethral colonization were compared to the occurrence of strains in the stool.

\section{Results}

Comparison of E. coli flora in hospitalized and nonhospitalized individuals. Based on a single stool culture from which 20 colonies of $E$. coli were sampled, the distribution of $O$ groups between the hospital and community was determined (Table II). The eight most common serogroups are listed separately. All other strains are included under the categories "other typable" and "nontypable." The last mentioned includes strains for which antisera were not available and strains 
TABLE II

Distribution of serogroups of $E$. coli between hospital and community based on total colonies in 74 patients

\begin{tabular}{|c|c|c|c|c|c|c|c|c|c|}
\hline \multirow[t]{2}{*}{ Serogroup } & \multirow[t]{2}{*}{$\begin{array}{c}\text { Total } \\
\text { colonies }\end{array}$} & \multicolumn{3}{|c|}{ E. coli hospital } & \multicolumn{2}{|c|}{ E. coli community } & \multirow{2}{*}{\multicolumn{2}{|c|}{$\begin{array}{c}\begin{array}{c}\% \text { of } \\
\text { sero group } \\
\text { found in } \\
\text { hospital }\end{array} \\
\% \\
71.3\end{array}$}} & \multirow{2}{*}{$\begin{array}{l}\text { p value* } \\
<0.001\end{array}$} \\
\hline & & $\begin{array}{c}\text { no. } \\
127\end{array}$ & $\begin{array}{l}\% \\
19.9\end{array}$ & & no. & $\begin{array}{l}\% \\
8.8\end{array}$ & & & \\
\hline 01 & 162 & 23 & 3.6 & & 139 & 24.1 & & 14.2 & $<0.001$ \\
\hline 0117 & 130 & 118 & 18.5 & & 12 & 2.1 &. & 90.8 & $<0.001$ \\
\hline 04 & 89 & 76 & 11.9 & & 13 & 2.2 & 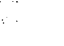 & 85.4 & $<0.001$ \\
\hline 075 & 72 & 48 & 7.5 & & 24 & 4.2 & & 66.7 & $<0.01$ \\
\hline 021 & 37 & 8 & 1.3 & & 29 & 5.0 & & 21.6 & $\dagger$ \\
\hline 016 or 062 & 33 & 1 & 0.2 & & 32 & 5.5 & & 3.0 & $\dagger$ \\
\hline 027 & 32 & 12 & 1.9 & & 20 & $\because \quad 3.5$ & & 37.5 & $\dagger$ \\
\hline $\begin{array}{l}34 \text { other typable } \\
\text { including cross } \\
\text { reactions }\end{array}$ & 482 & 225 & 35.2 & ' & 257 & $\begin{array}{r}: \quad:: \\
44.6\end{array}$ & $\therefore$ & 46.6 & $<0.05$ \\
\hline Total typable & 1,215 & 638 & 100 & & 577 & 100 & & 52.5 & \\
\hline Nontypable & 265 & 122 & & & $\therefore \quad 143$ & . & & 46.0 & $>0.05$ \\
\hline Total & $1 ; 480$ & 760 & & : & 720 & & : & 51.3 & \\
\hline
\end{tabular}

*Compared to total typable $E$. coli by $\mathrm{X}^{2}$ test.

$\uparrow$ Numbers too small for valid statistical analysis.

which remained in the rough state even after autoclaving. Of the entire group of 1,480 strains, $82.1 \%$ was typable. Of the five most common strains, four, namely $04,06,075$, and 01 , had been shown previously to be the most common pathogens in extraintestinal infections (6). The distribution between hospital and community of 04,06 , and 075 differed markedly from 01 and the remainder of E. coli. 04, 06, and 075 were found almost exclusively in the stools of hospitalized patients, whereas 01 was primarily a member of the community flora. 0117, which had not been regarded as a common pathogen in previous studies, was also concentrated within the hospital. These differences were highly significant. Although other strains may also fall in the hospital or community pools, they did not occur with sufficient frequency to lend themselves to statistical analysis. Six of the most prevalent strains in the stools of nonhospitalized patients were $01,06,021,011,075$, and 078 . Of these, only type 01 occurred with a frequency greater than would be expected by chance alone. Although the pool of 34 other typable strains was also somewhat more common in the community, no single strain occurred with sufficient frequency to make this observation meaningful. E. coli of groups 04,06 , and 075 together accounted for only about $15 \%$ of the community flora. The composition of the hospital flora was quite different. Group 01 was found infrequently, whereas 04,06 , and 075 together comprised nearly $40 \%$ of $E$. coli in the stools of hospitalized patients. Group 0117 was a relatively unique strain. Although rarely the cause of urinary tract or other extraintestinal infections in either this or a previous study (6), it tended to inhabit transiently the gastrointestinal tract of many hospitalized patients.

Table III summarizes the number of different strains of $E$. coli per the 20 colonies of each stool that was sampled. Although there were a few more polytypic stools among hospitalized patients, the difference between the number of serotypes in the stools of both groups was not statistically significant.

The distribution of $E$. coli related to duration

TABLE III

No. of strains of E. coli in stools of 36 hospitalized and 38 nonhospitalized individuals

\begin{tabular}{crrrrr}
\hline \multirow{2}{*}{$\begin{array}{c}\text { No. strains/ } \\
\text { Stool }\end{array}$} & \multicolumn{2}{c}{ Hospital } & & \multicolumn{2}{c}{ Community } \\
\cline { 2 - 3 } & no. & $\%$ & & no. & $\%$ \\
\hline 1 & 15 & 39.4 & & 12 & 33.3 \\
2 & 12 & 31.6 & & 16 & 44.5 \\
3 & 7 & 18.4 & & 8 & 22.2 \\
4 & 3 & 7.9 & & \\
5 & 1 & 2.7 & & \\
Total & 38 & 100 & & 36 & 100 \\
\hline
\end{tabular}


TABLE IV

Prevalence of serogroups of $E$. coli in hospitalized patients related to length of hospitalization

\begin{tabular}{|c|c|c|c|c|}
\hline \multirow[b]{3}{*}{ Serogroups } & \multicolumn{4}{|c|}{ Duration of hospitalization } \\
\hline & \multicolumn{2}{|c|}{$\begin{array}{c}\text { Less than } \\
20 \text { days } \\
\end{array}$} & \multicolumn{2}{|c|}{$\begin{array}{c}\text { More than } \\
20 \text { days }\end{array}$} \\
\hline & $\begin{array}{c}\text { Colo- } \\
\text { nies }\end{array}$ & $\begin{array}{c}\% \text { of } \\
\text { typable }\end{array}$ & $\begin{array}{c}\text { Colo- } \\
\text { nies }\end{array}$ & $\begin{array}{c}\% \text { of } \\
\text { typable }\end{array}$ \\
\hline $04,06,075$ & 119 & 27.8 & 132 & 62.9 \\
\hline 0117 & 105 & 24.5 & 13 & 6.2 \\
\hline Other typable & 204 & 47.7 & 75 & 30.9 \\
\hline Total typable & 428 & 100 & 210 & 100 \\
\hline
\end{tabular}

of hospitalization is summarized in Table IV. Although types $04,06,075$, and 0117 predominated in patients with relatively short hospital stay, many other strains were found. As hospitalization increased in duration, types 04, 06, and 075 became a progressively more prominent part of the hospital flora, and type 0117 tended to disappear from the stool. The three nosocomial strains, 04, 06 , and 075 , comprised nearly two-thirds of all typable strains in patients hospitalized for longer than 20 days.

Prevalence of groups in 102 men admitted for prostatectomy. As has been mentioned, the tabulation of occurrence of $\mathrm{O}$ groups by total number of colonies might tend to bias the results because additional weight would be given to stool samples monotypic for E. coli. Therefore, in the analysis of data to be presented subsequently, the results are tabulated according to the occurrence of the strain regardless of the number of colonies present or the number of cultures in which it appeared. The distribution of $E$. coli $\mathrm{O}$ groups between the community and the hospital was then determined in 102 men admitted to the hospital for prostatic surgery (Table V). A strain was defined as based in the community when it was found in the stool less than 48 hours after admission of a patient who had not been in contact with the hospital for at least 2 years. All other strains were considered to be hospital acquired. Other aerobic gram-negative rods including Pseudomonas, Klebsiella-Aerobacter, Proteus, Citrobacter, and intermediate coliforms were also identified in this study. $E$. coli belonging to serogroups $04,06,075$, and 0117 were rarely found among the community flora and comprised only about $12.5 \%$ of this group. These strains occurred almost exclusively within the hospital and accounted for $39 \%$ of $E$. coli cul- tured from the stools of hospitalized patients. This predominance in the hospital was probably more marked than indicated by these figures, since the "hospital" group was defined only by the lack of reasonable certainty that strains in it were acquired in the community. It is most likely that the hospital flora includes a number of strains that were carried in from the community. Furthermore, the length of hospitalization in this study seldom exceeded 3 weeks, when $E$. coli of these particular groups might be expected to be most prevalent. Other pathogenic gram-negative rods paralleled the distribution of $E$. coli belonging in $O$ groups 04, 06, 075, and 0117. Because they represent heterogenous groups, intermediate coliforms and nontypable $E$. coli were not compared statistically. These results indicate clearly that the stools of hospitalized patients are more commonly colonized by $E$. coli belonging to groups $04,06,075$, and 0117 as well as other pathogenic gram-negative rods than the stools of individuals not in contact with the hospital.

As was the case with the previous population, there were no significant differences in the number of $E$. coli strains per stool sample. The number of coliform strains per stool was approximately the same in hospital samples and those presumed to have originated in the community either before admission to or after discharge from the hospital. Alterations in stool flora following discharge from the hospital. Gram-negative organisms acquired in the community following discharge were studied with stool cultures obtained from patients who had had cultures of the stool just be-

TABLE V

Occurrence of gram-negative organisms in the hospital and community in the stools of 102 patients admitted for prostatectomy

\begin{tabular}{|c|c|c|c|c|}
\hline Strains & $\begin{array}{l}\text { Total } \\
\text { occur- } \\
\text { rence }\end{array}$ & $\begin{array}{c}\text { Occur- } \\
\text { rence } \\
\text { in hos- } \\
\text { pital }\end{array}$ & $\begin{array}{l}\text { Occur- } \\
\text { rence } \\
\text { in } \\
\text { com- } \\
\text { munity }\end{array}$ & p value* \\
\hline $04,06,075$, and 0117 & 59 & 54 & 5 & $<0.003$ \\
\hline Other typable $E$. coli & 119 & 84 & 35 & \\
\hline All typable $E$. coli & 178 & 138 & 40 & $>0.05$ \\
\hline Nontypable $E$. coli & 48 & 39 & 9 & $\begin{array}{c}\text { Not } \\
\text { compared }\end{array}$ \\
\hline Total E. coli . & 226 & 177 & 49 & $>0.05$ \\
\hline Intermediate coliform & 30 & 19 & 11 & $\begin{array}{c}\text { Not } \\
\text { compared }\end{array}$ \\
\hline $\begin{array}{l}\text { Other gram-negative } \\
\text { organisms }\end{array}$ & 100 & 86 & 14 & $<0.01$ \\
\hline
\end{tabular}

* Compared with other typable $F$. coli bv $\mathrm{X}^{2}$ test. 
fore discharge from the hospital and who had not had intervening hospital contact (Table VI). Of typable $E$. coli acquired following return to the community, only 2 of 20 typable strains were members of the hospital flora, a figure not dissimilar from that found at the time of admission in the same group of patients or in individuals not in contact with the hospital. Group 01 was acquired in the community on three occasions, whereas the remaining strains included four that had not been previously encountered in these patients. Although these data are limited in number, they support the concept that certain $E$. coli are concentrated in the hospital, whereas the remainder tend to be distributed at random throughout the community. An exception to this is $\mathrm{O}$ group 1 , which appears to be more prevalent in the community than in the hospital.

Persistence of strains in stools of hospitalized patients. One factor that might, in part, explain the increasing preponderance of certain $E$. coli in the stools of hospitalized patients is the ability of these strains to persist in the gut once colonization has occurred (Table VII). Persistence was defined as the continued presence of a given strain in the stool throughout the period of observation. $E$. coli of groups $04,06,075$, and 0117 persisted significantly more often than other strains of $E$. coli. In contrast, other pathogenic gram-negative bacilli were more transient inhabitants of the gastrointestinal tract. As will be shown subsequently, this observation may be related to the fact that these organisms usually originated in sources other than the gastrointestinal tract. Intermediate coliform organisms whose appearance may be related to the administration of antimicrobials (9) also tended to persist in the stools of hospitalized patients, but the number of occurrences of these

TABLE VI

Acquisition of gram-negative organisms following discharge from the hospital in 31 patients
Typable $E$. coli

04

06

01

15 other types,

Nontypable $E$. coli

Other gram-negative organisms

Total strains acquired
20

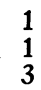

3
15

7

7

34
TABLE VII

Persistence of serogroups of $E$. coli and other gram-negative organisms in the stools of hospitalized patients

\begin{tabular}{lccccc}
\hline \hline Strains & $\begin{array}{c}\text { No. of } \\
\text { obser- } \\
\text { vations }\end{array}$ & $\begin{array}{c}\text { Per- } \\
\text { sist }\end{array}$ & Lost & $\begin{array}{c}\text { \% per- } \\
\text { sist }\end{array}$ & $\begin{array}{c}\text { p } \\
\text { value* }\end{array}$ \\
\hline $\mathbf{0 4 , 0 6 , 0 7 5 , \text { and } 0 1 1 7}$ & 50 & 34 & 16 & 68.0 & $<.05$ \\
$\begin{array}{l}\text { Other typable } E \text {. coli } \\
\text { Nontypable } E \text {. coli }\end{array}$ & 107 & 52 & 55 & 48.6 & \\
$\begin{array}{l}\text { Intermediate coliforms } \\
\text { Other gram- }\end{array}$ & 25 & 13 & 27 & 32.5 & \\
negative organisms & 81 & 31 & 50 & 38.3 & $\mathrm{NS}$ \\
\hline
\end{tabular}

* Compared with other typable $E$. coli by $\mathrm{X}^{2}$ test.

strains was too small to attach significance to this finding.

Occurrence of hospital infections. The relative rates of hospital-acquired infections and superinfections of different strains of $E$. coli and other gram-negative rods were compared, using the incidence of strains in the stool, i.e., the carrier rate, as a basis for comparison (Table VIII). O groups common within the hospital, 04, 06, 075, and 0117 , were responsible for urinary tract infections 13 times. All other typable E. coli caused only four infections, although the total number of occurrences in the stool of these strains was twice that of the first group. Other pathogenic gram-negative rods caused infection with a frequency similar to hospital $E$. coli. The ability of groups 04, 06, 075, and 0117 and other gramnegative pathogens to cause infection was significantly different from the infectivity of other strains. Nontypable $E$. coli and intermediate coliforms were slightly more prone to cause infections than community $E$. coli, but the number of infections was too small to attach significance to this observation. When the presence of a given strain of $E$. coli, in the stool before, or at, the time of onset of infection was analyzed, it was found that 11 of $17 \mathrm{E}$. coli were associated with carriage of the identical strain in the stool. In six instances the strain could not be detected in the stool even when up to an additional 100 colonies per stool culture were examined. In contrast, only seven of 25 infections with other gramnegative rods could be related to simultaneous fecal carriage, suggesting that the source of infection for these organisms was probably extraintestinal.

Ability of E. coli and other gram-negative organisms to colonize the urethra. The above.results indicate that most $E$. coli infections originate in the gut, whereas infections due to other gram- 
TABLE VIII

Occurrence of hospital-acquired urinary tract infection or superinfection related to incidence of gram-negative organisms in the stool

\begin{tabular}{|c|c|c|c|c|c|c|}
\hline Strains & $\begin{array}{c}\text { Total } \\
\text { stool } \\
\text { incidence }\end{array}$ & $\begin{array}{l}\text { Hospital- } \\
\text { acquired } \\
\text { infection }\end{array}$ & $\begin{array}{l}\text { Relative } \\
\text { infection } \\
\text { rate }\end{array}$ & p value* & $\begin{array}{c}\text { Infections } \\
\text { related to } \\
\text { simultaneous } \\
\text { stool } \\
\text { carriage }\end{array}$ & $\begin{array}{l}\% \text { stool } \\
\text { related }\end{array}$ \\
\hline & & & $\%$ & & & \multirow[b]{3}{*}{65} \\
\hline and 0117 & 59 & 13 & 22 & $<0.001$ & 9 & \\
\hline $\begin{array}{l}\text { Other typable } \\
\text { E. coli }\end{array}$ & 119 & 4 & 3.3 & & 2 & \\
\hline $\begin{array}{l}\text { Nontypable } \\
\text { E. coli }\end{array}$ & 48 & 3 & 6.2 & & 2 & 67 \\
\hline $\begin{array}{l}\text { Intermediate } \\
\text { coliforms }\end{array}$ & 30 & 3 & 10 & & 1 & 33 \\
\hline $\begin{array}{l}\text { Other negative } \\
\text { rods }\end{array}$ & 100 & 25 & 25 & $<0.001$ & 7 & 28 \\
\hline
\end{tabular}

* Compared with other typable $E$. coli by $\mathrm{X}^{2}$ test.

negative pathogens appear to have their source in extraintestinal sites. This difference might be accounted for in part, at least, by the ability of these two groups of organisms to colonize the urethra. This point was examined by comparing the occurrence of various strains within the urethra to their incidence in the stool (Table IX). Strains whose presence in the urethra could be explained by pre-existing urinary tract infection were excluded from this analysis. Although $E$. coli of $O$ groups $4,6,75$, and 117 colonized the urethra more frequently than other $E$. coli, this difference was not statistically significant. Other gram-negative organisms, however, were especially prone to inhabit the urethra. For ex-

TABLE IX

Occurrence of urethral colonization compared with stool incidence

\begin{tabular}{|c|c|c|c|c|c|}
\hline Strains & $\begin{array}{l}\text { Total } \\
\text { stool } \\
\text { inci- } \\
\text { dence }\end{array}$ & $\begin{array}{c}\text { Total } \\
\text { urethral } \\
\text { inci- } \\
\text { dence }\end{array}$ & $\begin{array}{l}\text { Relative } \\
\text { urethral } \\
\text { incidence }\end{array}$ & $\begin{array}{c}\text { Same } \\
\text { strain } \\
\text { in } \\
\text { urethra } \\
\text { and } \\
\text { stool } \\
\text { simul- } \\
\text { tane- } \\
\text { ously }\end{array}$ & $\begin{array}{l}\text { \% stool } \\
\text { related }\end{array}$ \\
\hline & & & $\%$ & & \multirow{3}{*}{69.2} \\
\hline $\begin{array}{l}04,06,075 \\
\text { and } 0117\end{array}$ & 59 & 17 & 28.8 & 10 & \\
\hline $\begin{array}{l}\text { Other typable } \\
\text { E. coli }\end{array}$ & 119 & 22 & 18.4 & 17 & \\
\hline $\begin{array}{l}\text { Nontypable } \\
\text { E. coli }\end{array}$ & 48 & 13 & 27.1 & 6 & 46.1 \\
\hline $\begin{array}{l}\text { Intermediate } \\
\text { coliforms }\end{array}$ & 30 & 15 & 50.0 & 6 & 40.0 \\
\hline $\begin{array}{l}\text { Other gram- } \\
\text { negative rods }\end{array}$ & 100 & 60 & $\begin{array}{r}\ddots 60.0 \\
\end{array}$ & 20 & $\begin{array}{c}3 \\
33.3 \\
\quad . \\
\end{array}$ \\
\hline
\end{tabular}

ample, these organisms were carried in the stool on 100 occasions, and the incidence of urethral carriage was $60 \%$ as opposed to 20 to $30 \%$ of $E$. coli. However, only one-third of the strains carried in the urethra was simultaneously found in the stool. These results provide further evidence that organisms other than $E$. coli enter the urethra from extraintestinal loci.

\section{Discussion}

There are several possible explanations for the finding that $E$. coli belonging to only a few serologic groups accounted for a large proportion of extraintestinal infections. First, these groups might simply be more prevalent in nature; second, these groups might be more prevalent in the hospital where many $E$. coli infections are acquired ; and third, these particular E. coli may possess enhanced infectivity in extraintestinal sites. Initially, we thought that the first of these explanations was the most likely. In a previous study (6), the distribution of $E$. coli in the stools of 30 patients with urinary infection was no different from that of 30 patients who did not have infection. However, that study was performed entirely in hospitalized individuals. Furthermore, even in that group of patients, those without infections tended to harbor a higher number of $E$. coli belonging to $O$ group 1 , suggesting that this particular group is more common in carriers without infections than in patients with bacteriuria. It is also quite clear that the previous study consisted 
of a heterogenous, relatively poorly defined population group whose origin with respect to hospital or community was not clear. Furthermore, the present study would contradict the first hypothesis because the three most common extraintestinal pathogens found in two previous studies $(6,7)$ comprised only 10 to $15 \%$ of the fecal E. coli flora found in the community. This relatively low rate of carriage of the three common serotypes in the community held true for several different populations whether these were compared with a single stool culture or whether they were patients who were eventually hospitalized and served as their own controls in the community. The evidence presented in this report suggests that both the second and third hypotheses, namely increased dissemination of a few strains of $E$. coli in the hospital and enhanced infectivity in extraintestinal sites, are responsible for the uneven distribution of $E$. coli in extraintestinal infections. Both of the studies described in this report clearly indicate that the common strains 04,06 , and 075 are concentrated within the hospital and comprise a progressively increasing proportion of the patient's fecal flora as hospitalization progresses. This means that these strains have a greater opportunity to produce extraintestinal infection. In addition, however, strains of serogroups 04,06 , and 075 cause infections out of proportion to their occurrence in the hospital environment. Since most $E$. coli infections have their locus of origin in the gut flora, each strain present in the stool should presumably have an equal opportunity to produce an extraintestinal infection. It is clear, however, that although strains other than 04,06 , and 075 were carried in the stool as frequently as these common groups, only the latter caused a significant number of infections. Further evidence to support these hypotheses is found in the marked parallelism in both hospital concentration and incidence of infection of E. coli 04,06 , and 075 and other pathogenic gram-negative rods that are well known for their association with hospital-acquired infections (10-12). Although it is true that gramnegative pathogens other than $E$. coli gain access to the urinary tract from extraintestinal sites, a route that has been previously well documented $(13,14)$, these organisms, as well as nosocomial $E$. coli, appear to possess enhanced epidemiologic virulence.
The concept of epidemiologic virulence was introduced by Fekety and Bennett (15) to describe the epidemiologic behavior of the $80 / 81$ phage type staphylococcus. These authors demonstrated that this particular strain caused infection with far greater frequency relative to the carrier state than staphylococci of other phage types. The same can be said for E. coli 04, 06, and 075 , which also appear to produce infection more commonly than other serogroups of $E$. coli even when their high rate of carriage in the hospital is taken into consideration.

The work of Kunin, Deutscher, and Paquin (16) showing that $E$. coli of $O$ groups 4,6 , and 75 are also the chief cause of urinary tract infections in school children, most of whom presumably acquired their infection in the community, would seem to contradict the present study. On the other hand, their results are entirely consistent with the increased infectivity of these strains and suggest that although the carriage rate of these strains is relatively low outside the hospital, their increased infectivity is responsible for the relative frequency with which they are found in $E$. coli infections not acquired in the hospital. A systematic study of community-acquired $E$. coli infections and the relationship of fecal carriage to these infections has not been performed and is essential if this point is to be settled with certainty.

Serologic characterization of $E$. coli in these studies was not complete since only the $\mathrm{O}$ antigens, and not $\mathrm{H}$ or $\mathrm{K}$ antigens, were determined. In previous epidemiologic investigations we have not found these two antigens of value in characterizing large populations of $E$. coli (6). These antigens have been helpful primarily in clarifying the course of urinary tract infection in single patients, and specifically in determining whether a recurrent infection represents reinfection from without or recrudescence of endogenous infection.

Although E. coli of groups 04, 06, and 075 paralleled other gram-negative organisms in their ability to colonize the stool of hospitalized patients and to produce infections relatively frequently, only $E$. coli were present in the stools of most patients who acquired infections; other gramnegative organisms were located primarily in the urethra rather then the stool. This resulted in the suggestion that gram-negative infections other than $E$. coli emanated from outside the gut whereas 
E. coli infections originated primarily in the patient's stool. This hypothesis certainly explains these differences, but does not exclude the possibility that in some instances $E$. coli infections may also originate in extraintestinal sites. Careful culturing of areas other than the patient's stool, urethra, and urine will be required to answer this question.

It might be argued that the population in the present study, elderly men undergoing prostatectomy, all with indwelling catheters for various lengths of time, is not representative of hospital populations in general, and that the infections acquired by this route may not reflect the typical E. coli infection. This may be partially true, but infections occurring after instrumentation represent a major portion of hospital-acquired $E$. coli infections (10). Furthermore, any attempt to relate rates of infection to the prevalence of strains in the carrier state must utilize a population whose flora is defined before the onset of infection. This is technically feasible only in a group whose rate of infection is relatively high such as patients requiring indwelling catheters. Finally, there is some evidence that hospital-acquired $E$. coli infections may occur in sites other than the urinary tract. For example, there have been two hospitalassociated outbreaks of urinary tract infection in newborns due to $E$. coli $04(17,18)$. Lastly, Rantz's observation that $E$. coli 06 is the most common strain in the stools of children who had hospital contact also supports the nosocomial origin of this particular serologic group (7).

The mechanisms by which these relatively few specific $E$. coli tend to predominate in the hospital population are not clear. Contrary to the situation with Staphylococcus aureus, resistance to antibiotics does not appear to play a major role (19). Production of certain colicines may influence the intestinal flora and may be an important factor in its composition (20). This subject is currently under investigation. The mode of transmission of these $E$. coli within the hospital is also not well understood. It is likely, however, that these organisms are carried on the hands of hospital personnel and on inanimate objects. Certainly, many items of hospital equipment have been implicated in the spread of gram-negative organisms other than $E$. coli (21).

The $E$. coli flora of the intestine changes peri- odically under normal circumstances (22). Sometimes this alteration is very rapid, and the serology may change as often as every day. When these changes occur in the hospital, nosocomial strains appear and replace those that are lost. These nosocomial coliforms are, in turn, shed when the patient returns to the community.

As with the staphylococcus, the factors influencing the enhanced infectivity or virulence of $E$. coli are poorly understood. Strains of various serologic groups do not differ with respect to their ability to produce experimental pyelonephritis (23) or to evoke elaboration of hemagglutinating antibodies (24). Bactericidal activity of normal serum has differed with respect to different groups of $E$. coli. In general, the strains most frequently responsible for infection have been most resistant to the killing effect of normal serum (25). It is conceivable that this particular host defense mechanism may be important in rendering certain individuals prone to infections with these particular strains.

Whenever an organism exists symbiotically with the host in one location but produces infection in another, the host-parasite relationship is necessarily complex. Nowhere is this more true than in infections caused by $E$. coli. In view of the increasing importance of these organisms in causing infections, particularly in elderly debilitated patients confined to the hospital $(26,27)$, further studies to clarify the conditions that facilitate the carrier state of $E$. coli in man and determine whether infection will take place are clearly indicated. A point of departure for these studies would be to study these relationships in a bacteriologically clean environment in which each variable could be assessed separately.

\section{Summary}

1. The E. coli serogroups that are most often responsible for extraintestinal infections, 04, 06, and 075 , are concentrated within the hospital and constitute a nosocomial flora. The remaining serologic groups are distributed at random throughout the hospital and the community. O group 1 is an exception in that it appears to be predominantly a community strain.

2. Using prevalence in the stool carrier state as the denominator, $E$. coli of $O$ groups 4,6 , and 
75 cause urinary tract infection with significantly greater frequency than strains of other serologic groups.

3. E. coli of serogroups 04,06 , and 075 resemble Pseudomonas, Klebsiella-Aerobacter, Proteus, and Citrobacter in their association with the hospital and their propensity to cause urinary tract infections.

4. E. coli of serogroups 04,06 , and 075 tend to persist within the gastrointestinal tract and may account, in part, for the increased hospital prevalence.

5. E. coli urinary tract infections are usually associated with colonization in the stool by the same organism. On the other hand, urinary tract infections caused by other gram-negative pathogens are usually acquired from external sources.

\section{References}

1. Kauffmann, F. The serology of the coli group. J. Immunol. 1947, 57, 71.

2. Edwards, P. R., and W. H. Ewing. Identification of enterobacteriaceae. Minneapolis, Burgess, 1955.

3. Ewing, W. H. Enteropathogenic Escherichia coli serotypes. Ann. N. Y. Acad. Sci. 1956, 66, 61.

4. Kessner, D. M., H. J. Shaughnessy, J. Googins, C. M. Rasmussen, N. J. Rose, A. L. Marshall, Jr., S. L. Andelman, J. B. Hall, and P. J. Rosenbloom. An extensive community outbreak of diarrhea due to enteropathogenic Escherichia coli 0111: B4. I. Epidemiologic studies. Amer. J. Hyg. 1962, 76, 27.

5. Boris, M., B. M. Thomason, V. D. Hines, T. S. Montague, and T. F. Sellers, Jr. A community epidemic of enteropathogenic Escherichia coli 0126:B16:NM gastroenteritis associated with asymptomatic respiratory infection. Pediatrics 1964, 33, 18.

6. Turck, M., and R. G. Petersdorf. The epidemiology of non-enteric Escherichia coli infections: prevalence of serological groups. J. clin. Invest. 1962, 41, 1760.

7. Rantz, L. A. Serologic grouping of Escherichia coli: study in urinary tract infection. Arch intern. Med. 1962, 109, 37.

8. Vosti, K. L., A. S. Monto, and L. A. Rantz. The importance of sample size in studies based upon the serologic elassification of Escherichia coli. Proc. Soc. exp. Biol. (N. Y.) 1962, 111, 201.

9. Lindemeyer, R. I., M. Turck, and R. G. Petersdorf. Factors determining the outcome of chemotherapy in infections of the urinary tract. Ann. intern. Med. 1963, 58, 201.

10. Sanford, J. P. Hospital-acquired urinary-tract infections. Ann. intern. Med. 1964, 60, 903.
11. Grossberg, S. E., R. G. Petersdorf, J. A. Curtin, and I. L. Bennett, Jr. Factors influencing the species and antimicrobial resistance of urinary pathogens. Amer. J. Med. 1962, 32, 44.

12. Omland, T. Nosocomial urinary tract infections caused by Proteus rettgeri. Acta path. microbiol. scand. 1960, 48, 221.

13. Dutton, A. A. C., and M. Rạlston. Urinary tract infection in a male urological ward, with special reference to the mode of infection. Lancet 1957, 1, 115.

14. Kippax, P. W. A study of Proteus infections in a male urologic ward. J. clin. Path. 1957, 10, 211.

15. Fekety, F. R., and I. L. Bennett, Jr. The epidemiological virulence of staphylococci. Yale J. Biol. Med. 1959, 32, 23.

16. Kunin, C. M., R. Deutscher, and A. Paquin, Jr. Urinary tract infection in school children : an epidemiologic, clinical and laboratory study. Medicine (Baltimore) 1964, 43, 91.

17. Sweet, A. Y., and E. Wolinsky. An outbreak of urinary tract and other infections due to $E$. coli. Pediatrics 1964, 33, 865.

18. Kenny, J. F., D. N. Medearis, Jr., R. H. Drachman, L. E. Gibson, and S. W. Klein. An outbreak of urinary tract infections and septicemia due to Escherichia coli in male infants (abstract). Amer. J. Dis. Child. 1962, 104, 461.

19. Kennedy, R. P., J. J. Plorde, and R. G. Petersdorf. Unpublished data.

20. Branche, W. C., Jr., V. M. Young, H. G. Robinet, and E. D. Massey. Effect of colicine production on Escherichia coli in normal human intestine. Proc. Soc. exp. Biol. (N. Y.) 1963, 114, 198.

21. McLeod, J. W. The hospital urine bottle and bedpan as reservoirs of infection by Pseudomonas pyocyanea. Lancet 1958, 1, 394.

22. Wallick, H., and C. A. Stuart. Antigenic relationships of Escherichia coli isolated from one individual. J. Bact. 1943, 45, 121.

23. Kimball, H., M. Turck, and R. G. Petersdorf. The epidemiology of nonenteric Escherichia coli infections. III. Relationship of $E$. coli antigens to experimental pyelonephritis. J. Lab. clin. Med. 1964, 63, 907.

24. Kunin, C. M. Antibody distribution against nonenteropathic $E$. coli. Relation to age, sex, and breast feeding. Arch. intern. Med. 1962, 110, 676.

25. Kimball, H., M. Garcia, and R. G. Petersdorf. The epidemiology of nonenteric Escherichia coli infections. II. Relationship of prevalence of $E$. coli in urinary infections to the bactericidal effect of human serum. J. Lab. clin. Med. 1964, 63, 901.

26. Finland, M., W. F. Jones, Jr., and M. W. Barnes. Occurrence of serious bacterial infections since introduction of antibacterial agents. J. Amer. med. Ass. 1959, 170, 2188.

27. Rogers, D. E. The changing pattern of life-threatening microbial disease. New Engl. J. Med. 1959, 261,677 . 